ICOFOM Study Series

\title{
Remirar el museo desde el escenario brasileño
}

To reinterpret the museum in the Brazilian context

\section{Alejandra Saladino}

\section{(2) OpenEdition}

Journals

Edición electrónica

URL: http://journals.openedition.org/iss/2815

DOI: $10.4000 /$ iss. 2815

ISSN: 2306-4161

Editor

ICOM - International Council of Museums

Edición impresa

Fecha de publicación: 15 diciembre 2020

Paginación: 208-224

ISBN: 978-2-491997-27-4

ISSN: 2309-1290

Referencia electrónica

Alejandra Saladino, «Remirar el museo desde el escenario brasileño», ICOFOM Study Series [En línea], 48-2 | 2020, Publicado el 26 enero 2021, consultado el 06 febrero 2021. URL: http://

journals.openedition.org/iss/2815 ; DOI: https://doi.org/10.4000/iss.2815 


\section{Remirar el museo desde el escenario brasileño}

\section{Alejandra Saladino \\ Universidad Federal del Estado de Río de Janeiro - Río de Janeiro, Brasil}

\section{RESUMEN}

El campo de los museos en Brasil presenta interesantes e inspiradoras experiencias que ponen en evidencia el carácter social y político de esas instituciones. Teniendo en cuenta el rol de los museos en el campo del patrimonio cultural, se propone reflexionar sobre las implicaciones prácticas, administrativas y legales en el uso de la definición de museo propuesta por ICOM en 2019 en el escenario actual de Brasil. El análisis de los datos recolectados sobre el contexto museístico brasileño de las últimas décadas se fundamenta en la corriente teórica del Institucionalismo Histórico. Los resultados de esa reflexión preliminar sugieren que las decisiones institucionales que resultaron en la Política Nacional de Museos coinciden con los principios de la definición de museo recién propuesta y que la adopción de ella podría resultar en una estrategia para recuperar y fortalecer aquellas mismas políticas públicas.

Palabras clave: Museo, definición, políticas públicas, Brasil 


\section{A B STRACT}

\section{To reinterpret the museum in the Brazilian context}

The field of museums in Brazil presents interesting and inspiring experiences that highlight the social and political nature of these institutions. Having in mind the role of museums in the field of Cultural Heritage, I propose to reflect on the practical, administrative and legal implications of the use of the definition of "museum" proposed by ICOM in 2019 in the current scenario of Brazil. The analysis of the data collected on the Brazilian museological context of the last decades is based on the theoretical current of Historical Institutionalism. The results of this preliminary reflection suggest that the institutional choices that resulted in the National Museum Policy coincide with the principles of the new definition of "museum" proposed and that its adoption could result in a strategy to recover and to strength those same public policies.

Keywords: Museology, definition, public policies, Brazil

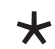

Lo que caracteriza a un museo es la intención con la que fue creado y el reconocimiento público (lo más amplio posible) de que es efectivamente un museo, es decir, una institución auténtica. El museo es el sitio del hecho "museal"; pero para que esto suceda concretamente, es necesario "musealizar" los objetos (objetos materiales y objetos conceptuales). Así podemos "musealizar" objetos que son vestigios, evidencias de la existencia del hombre y de su ambiente, natural o modificado por él mismo.

Waldisa Russio

(Bruno, 2010b, p.124-125)

Un mundo en transición, donde las estructuras antiguas se desmoronan; donde los patrones estéticos y morales se sacuden violentamente; donde las desigualdades de desarrollo hacen que el diálogo entre naciones sea equívoco; donde el hombre lucha por convertir la máquina en su ayudante, liberándose de su yugo; donde el hombre huye de la metrópoli y las formas de vida antihumanas que él mismo ha creado; donde el conocimiento humano acumulado permite un progreso científico rápido e incesante que el hombre mismo teme; donde los medios transforman la tierra en una aldea global, sí, pero donde la comunicación es filtrada por la máquina del Estado o por la élite económica que posee los medios de comunicación.

Waldisa Russio

(Bruno, 2010a, p.54) 
Este texto tiene por objetivo presentar el resultado del desafío asumido de reflexionar sobre las implicaciones prácticas, administrativas y legales en el uso de la definición de museo propuesta por ICOM en 2019, teniendo en cuenta el escenario actual de Brasil. Se trata de un reto por lo complejo del contexto actual, impactado por la pandemia del COVID-rg y por la crisis del sector cultural bajo presiones del campo político y económico. Teniendo en cuenta la trayectoria de las políticas para los museos, se acepta la propuesta de intentar contestar a las siguientes preguntas: ¿Cómo la definición de museo del ICOM especifica las prácticas y las políticas públicas locales al generar estándares y reglas para su forma de actuar? ¿Qué instituciones están incluidas, desde una perspectiva legal, política y financiera, en la categoría de "museo"? ¿Cuáles están excluidas y luchan por obtener reconocimiento público y financiero?

Las reflexiones se presentan en dos partes. La primera enseña una mirada, a vuelo de pájaro, sobre las políticas del sector de museos en Brasil, pero en el contexto más amplio de las políticas públicas de cultura y de patrimonio cultural. En la segunda parte se exponen algunas reflexiones sobre las implicaciones prácticas, administrativas y legales en el uso de la definición de museo propuesta por ICOM en 2019 en el escenario actual de Brasil, teniendo en cuenta la conyuntura actual.

No obstante, antes de presentar esos ítems, es importante aclarar algunos conceptos clave para esta mirada y también las perspectivas teóricas desde las cuales se analisa el tema. En primer lugar, hay que diferenciar las nociones de política cultural y política pública de cultura.

La idea de política cultural está fundamentada en las miradas del antropólogo Néstor García Canclini (2005) y del sociólogo, Antonio Canelas Rubim (2007), y la historiadora Lia Calabre (2007), que lo acompañan a él. Concreta y sencillamente, las políticas culturales son arreglos técnicos y administrativos derivados de decisiones políticas, realizadas por el Estado, los organismos civiles y los grupos comunitarios" (García Canclini, 2005, pp.78), pero "teniendo en cuenta el carácter transnacional de los procesos simbólicos y materiales en la actualidad (García Canclini, 2005, pp.78). Luego, las políticas culturales pueden plantearse y ser activadas también por agentes no estatales.

La noción de política pública de cultura está basada en la definición propuesta por la socióloga Anita Simis (2007), tratándose de directivas generales derivadas de una decisión política y dirigidas al interés público, cuya responsabilidad es predominantemente de los órganos gubernamentales.

La base para los argumentos aquí expuestos está en el Institucionalismo Histórico. Se trata de una variable del Neoinstitucionalismo, una corriente de la Teoría Política adecuada para observar e interpretar contextos y procesos institucionales porque enfocada en los valores, padrones y prácticas institu-

I. Para profundizar sobre el concepto de políticas de cultura, véase la propuesta de modelo analítico desarrollado por Antônio Canelas Rubim (2006). 
cionales, teniendo en cuenta la trayectoria de la institución, sus rutinas y cambios a lo largo del tiempo. Desde ese cuadro teórico se puede identificar que las/os las/os agentes implicadas/os comparten los valores (que constituyen la institución y fundamentan sus prácticas y políticas) de forma más o menos fiel y/o intensa y según los roles e intereses que representan.

Además, desde el Institucionalismo Histórico se puede observar el fenómeno de la dependencia de la trayectoria (Hall, \& Taylor, 2003), es decir, la tendencia de mantener, a lo largo del tiempo, los valores correspondientes a las primeiras decisiones institucionales, conservadas en las prácticas rutinizadas, aunque sean estas revisadas y actualizadas.

Según las bases de esta perspectiva, los cambios institucionales suceden cuando cambian los valores. Las razones derivan tanto de presiones endógenas (como, por ejemplo, la asimetría de fuerzas entre grupos que participan del sector, unos imponiendo sus visiones y prioridades, tales como enfocar la dimensión socio-educativa de los museos a la vez de la dimensión preservacionista del patrimonio) y exógenas (derivadas de imposiciones de orden político, económico y social, entre otros, los cortes presupuestarios en momentos de crisis financieras y la censura a exposiciones).

Además, a partir de estos puntos de vista teóricos, se puede observar el sector de los museos como una institución constituída por un complejo conjunto de normas, convenciones, marcos jurídico-legales, entidades (tales como los museos, centros de investigación, asociaciones, como el ICOM, redes de museos $\mathrm{y}$ de profesionales etc) y distintos segmentos sociales (como los profesionales de museos, los públicos y comunidades vecinas). Los agentes involucrados en esa institución, es decir, el sector de los museos, comparten algunos principios y valores que fundamentan sus discursos y sus prácticas que, transformándose en rutinas, terminan por constituirse como patrones².

El método combinado con el Institucionalismo Histórico está basado en una revisión bibliográfica sobre el tema, con la cual se compuso un panorama del contexto, articulando las políticas públicas de cultura, de patrimonio cultural y de museos.

Los resultados alcanzados sugieren que las decisiones institucionales que resultaron en la Política Nacional de Museos (PNM) coinciden con los principios de la definición de museo recién propuesta y que la adopción de ella podría resultar en una estrategia para recuperar y fortalecer aquellas mismas políticas públicas.

2. En este texto, la palabra institución se utiliza con el sentido atribuido desde el institucionalismo histórico. 


\section{Una mirada sobre el sector de museos de Brasil}

Teniendo en cuenta el contexto de las políticas de cultura y desde la perspectiva del institucionalismo histórico, se presenta una mirada sobre el sector museal ${ }^{3}$ de Brasil, pero en el contexto más amplio del campo de la cultura y del patrimonio cultural. Son recalcados solamente algunos hitos de las políticas para museos, aquellos más marcantes y que puedan explicar el estado del arte ${ }^{4}$, puesto que trazar un histórico o un panorama más completo sobrepasaría los objetivos de esta propuesta y también los límites formales sobre el cual se redactó este texto.

Antes de nada, resulta importante señalar un aspecto, referente al inicio de las políticas de cultura en Brasil. En consonancia con Calabre (2007) y Rubim (2007), se identifican a inicios del gobierno dictatorial de los años i93o los empeños para la implantación, por primera vez en nivel nacional, de políticas públicas para el sector. De ese momento, destacamos la creación de una ley de preservación de patrimonio cultural y algunas entidades como, por ejemplo, el Instituto Nacional del Libro, el Consejo Nacional de Cultura y una organización dedicada al patrimonio cultural, actualmente nombrada Instituto del Patrimonio Histórico y Artístico Nacional/IPHAN5.

Considerando esas cuestiones, y a la luz del institucionalismo histórico, se puede observar en la historia de las políticas públicas en Brasil la tendencia de los gobiernos autoritarios a plantear políticas para el sector, pues este hecho también se nota en el período de la dictadura civil-militar (I964-1985). Rubim (2007) define la inclinación a la relación entre políticas de cultura y autoritarismo como "triste tradición".

Todavía, resulta importante marcar que esa inclinación de los gobiernos opresores estableceren políticas públicas, especialmente de patrimonio cultural, no es algo que se nota solo en el caso de Brasil. Durante el siglo XX, la importancia y el poder del discurso del patrimonio fue reconocido en otros gobiernos autoritarios como, por ejemplo, el Estado Novo del presidente António de Oliveira Salazar, cuando se creó, en I929, la Dirección General de Edifcios y Monumentos Nacionales.

De los intentos de consolidación de políticas públicas de cultura en Brasil en aquellos dos momentos (concretamente, el período del gobierno dictato-

\footnotetext{
3. En este artículo, el concepto museal representa el "campo práctico y aplicado de los museos" (Blog História da Museologia).

4. El tema de las políticas públicas de cultura sobrepasa los objetivos y los límites formales de este artículo. Para profundizar el asunto, véase Lia Calabre (2007; 2013; 2014), Antonio Rubim (2006, 2007) y Anita Simis (2007).

5. Para profundizar sobre la historia del patrimonio cultural en Brasil, destacando la actuación del IPHAN, véase la obra de la historiadora Cecília Londres Fonseca (2005).

6. El autor identifica "tres tradiciones tristes" de las políticas culturales en el país: la ausencia de políticas, la innestabilidad de ellas y su relación con gobiernos opresores (Rubim, 2006; 2007).
} 
rial del presidente Getúlio Vargas y el período del gobierno de la dictadura civil-militar) es importante señalar dos aspectos. El primero trata del empeño en identificar y valorar las representaciones identitarias y expresiones culturales que definen y caracterizan la cultura brasileña. El segundo se refiere a la estrategia de desarrollar esos procesos con el apoyo y la actuación de destacados intelectuales y expertos de la época.

Los valores que fundamentaban los discursos y las acciones del Estado sobre la cultura y el patrimonio en el primer intento de institución de políticas públicas estaban relacionados a la idea de nación, de existir un atributo singular de ser brasileña/o, a la valorización del trabajo, de existir un tipo de harmonía entre las clases sociales y, por último, de pueblo mestizo (Rubim, 2007, pp.i6-i7). Participaron de esa producción importantes intelectuales, peritos y agentes culturales, algunos de ellos involucrados con el Movimiento Modernista de los años $192 \mathrm{O}^{7}$.

Hay que subrayar el importante rol del IPHAN para el sector cultural, con sus discursos y prácticas de valoración y preservación del patrimonio, inclusos los museos. Las primeras decisiones institucionales del IPHAN enfocaban, principalmente, los bienes culturales inmuebles de valor excepcional y monumental relacionados con algunas matrices culturales. Otras opciones se refieren al sector museal, dirigidas estas para la incorporación de museos nacionales (como el Museo Histórico Nacional) y la creación de museos de cariz regional en distintas ciudades y/o sitios de destacado valor histórico (tales como el Museo de Misiones, en el Estado de Rio Grande do Sul, y el Museo del Diamante, en el Estado de Minas Gerais).

Pasado el gobierno ditactorial del presidente Getúlio Vargas, en 1945, sucede un ciclo democrático hasta 1964, cuando empieza el otro ya aludido período dictatorial. En esos años post Segunda Guerra Mundial, a pesar de la creación del Ministerio de Educación y Cultura (1953) y de las acciones de preservación del IPHAN, en el sector cultural se notan apenas actividades puntuales. En otros términos, las políticas públicas planteadas en la época anterior no se consolidaron como políticas de Estado (Rubim, 2007). Pero se puede señalar la actuación del sector privado en la creación de museos, como el Museo de Arte Moderno de Río de Janeiro y el Museo de Arte de São Paulo.

En el segundo período dictatorial en el cual el gobierno planteó políticas culturales destacan los objetivos de preservación del patrimonio cultural, de incentivo a la creatividad y de difusión de la creación artística. Del sector museal se marcan las acciones de preservación de algunos lugares de memoria ${ }^{8}$

7. Para profundizar sobre el asunto, véase Fonseca (2005) y Nogueira (2005).

8. Utilizamos este concepto con el sentido propuesto por el historiador Pierre Nora (1993), es decir, para definir lugares (concretos y/o simbólicos) donde se plasman los fragmentos que no son más espontáneos y por eso, hay que ritualizarlos en acciones (como celebraciones y registros) que constituyen la memoria histórica. 
importantes para la consolidación de esa política, como el Museo Nacional de Bellas Artes.

En los años i970, la estrategia del gobierno autoritario consistía en no perder el control ni la hegemonía en el proceso de transición para el período democrático (Rubim, 2007). Para eso, aumentaron las inversiones para el sector, algunos de los más destacados intelectuales y expertos fueron invitados a participar de las políticas, se creó el primer Plan Nacional de Cultura/PNC y se crearon muchos organismos, como la Fundación Nacional de las Artes/FUNARTE (Ortiz; Miceli apud Rubim, 2007, pp.2I). Por fin, se consideraron las recomendaciones de UNESCO para la cultura como, por ejemplo, la UNIDROIT/UNESCO, de I972, y la Declaración de México/ICOMOS, de I982 (Rubim, 2007, pp.22).

Estas acciones derivaron de la renovación de los valores y los discursos del campo de la cultura y del patrimonio cultural, desde la adopción del concepto antropológico de cultura y de referencia cultural. Además, posibilitaron que se plantasen las semillas para la creación de un Ministerio de Cultura, lo que sucedió ya en un nuevo período democrático, en I985.

Aunque empezara con problemas presupuestarios, administrativos y de infra-estructura, el Ministerio de Cultura propuso por primera vez una política para el sector museal, con la propuesta de creación de un Sistema Brasileño de Museos/SBM, articulado con los sistemas estaduales del área (Nunes, 2018). Destaca de este período la creación de una ley de incentivo a proyectos culturales, basada en exenciones fiscales, que inaugura en el sector cultural la práxis de transferir al ramo privado el poder de decidir cuáles proyectos recibirían recursos públicos" (Calabre, 2007, pp. 8).

Importa destacar de ese período, como resultado de la articulación del sector cultural y de la actuación de sus entidades, la presencia del tema de la cultura y del patrimonio en la Constitución Federal de i988, donde se define qué es el patrimonio cultural brasileño (en consonancia con el concepto antropológico de cultura y los principios de las convenciones internacionales) y el rol de la sociedad en su preservación.

La primera década del siglo XXI está enmarcada por hitos importantes en el sector cultural, resultado de la "construcción real del Ministerio de Cultura" (Calabre, 2007, pp. Io) y del primer intento de consolidar políticas públicas bajo un régimen democrático y con activa participación de la sociedad. Este ministerio, en la gestión del artista Gilberto Gil, se puso en fuerte consonancia con los valores y los principios de los documentos internacionales, incluso la Declaración Universal de los Derechos Humanos. Entre estos, destacan las premisas de la cultura como derecho básico, de la diversidad cultural y de la cultura como elemento importante para la inclusión social y el fortalecimiento de una ciudadanía democrática y cultural. Desde esta ciudadanía, según Calabre

9. Para profundizar sobre el tema de las políticas de inversión para el sector cultural, véase Calabre (2007; 2013; 2014) y Rubim (2007). 
(2007), se podría superar las desigualdades sociales y reconocer la diversidad cultural y social del país.

De hecho, estaba clara la intención de implantar y consolidar políticas públicas para que la cultura pudiera transformarse en una herramienta de valorización de la diversidad cultural, de sanación de desigualdades sociales y de empoderamiento social. Constaba que el Ministerio era el espacio de la memoria y de la innovación, de la tradición y de la invención. Por eso, en la gestión de Gilberto Gil se intentó que el Ministerio se transformara en un lugar de experimentación de posturas, de discursos, de caminos y de prácticas cuyos objetivos eran el acceso universal a los bienes culturales, la facilitación de las condiciones para creación y la producción de bienes culturales y promoción de la economía de la cultura.

El Ministro tenía muy clara la responsabilidad del Estado en la consolidación de las políticas, y en su discurso de investidura, en 2003, subrayó una de las tareas de su gestión: cambiar el sentido de las políticas de financiación fundamentadas en el mercado (el desarrollo de proyectos desde exenciones de impuestos) para lograr "corregir distorsiones inherentes a la lógica del mercado, que siempre se rige, en última instancia, por la ley del más fuerte" (Gil, 2003). Por tanto, se trataba de un período innovador por intentar crear una cultura de formulación de políticas públicas para el sector y también de poner a Brasil en evidencia internacional, como sitio de una sociedad multicultural capaz de desarrollar, desde la cultura, cambios sociales.

Desde articulaciones entre gobiernos (federal, estadual y municipal) y segmentos sociales y profesionales, se propuso un nuevo PNC (una especie de brújula para el planeamiento y la implementación de las políticas culturales dirigidas a la promoción de la diversidad cultural, artística y étnica, compuesto de planes para los distintos sectores como, por ejemplo, los museos) y también un Sistema Nacional de Cultura/SNC, que se encargaría de gestionar las políticas desde la reglamentación de las competencias de los distintos sectores involucrados.

Del sector de museos hay que subrayar la creación, en 2003, da la Política Nacional de Museos/PNM, resultado de colaboraciones entre las/los agentes no estatales y distintos organismos (IPHAN y sistemas estaduales de museos), concordante con los documentos de UNESCO y con las directrices del Ministerio de Cultura ${ }^{\text {Io }}$.

En nivel institucional, la creación en el IPHAN, en 2004, de un departamento dedicado a los museos fue estratégica para la consolidación de la PNM y para el fortalecimento de las articulaciones del sector museal en distintos niveles administrativos, políticos e institucionales. Destacan algunos efectos, como la creación del SBM, de un Plan Nacional para Museos (vinculado al PNC vigente durante el período 20I0-2020), una ley para los museos del país (Ley n.

Io. Sobre los objetivos estratégicos, ejes programáticos, instrumentos y dinámica de la PNM, véase La Política Nacional de Museos. Memoria y ciudadanía (Iphan, 2003). 
II.904/2009) y el Instituto Brasileiro de Museus/IBRAM. Además, con carácter internacional, se señála la participación en acciones en colaboración con países de Iberoamérica.

Las estrategias de motivar la participación y el activismo de los agentes del sector museos resultó en la creación de distintas redes, como la Red de Educadores de Museos/REM (elemento fundamental para la creación de la Política de Educación Museal/PNEM), la Red de Accesibilidad en Museos, las Redes de Museología Social, la Red de Museos y Acervos Arqueológicos, las redes de museos indígenas etc. Estas redes actúan como importantes herramientas de consolidación, reivindicación y fortalecimiento de la PNM y luego del área de los museos.

Desde la PNM se ha pretendido reforzar las dimensiones política, social y económica de los museos. Para ello, se crearon instrumentos de fortalecimento del sector (los talleres de capacitación y el catastro de museos, que ha sido fundamental para orientar las estratégias de consolidación del sector), de gestión (el plan museológico) y de inversión (convocatorias y programas). De esa manera, el sector sintonizaba con los ejes y objetivos estratégicos del Ministerio de Cultura, donde la cultura se tomaba como factor de cambio social y de desarrollo sostenible. Por eso, se realizaron estudios sobre economía de la cultura y el rol de los museos brasileños en la economía y el desarrollo social (Ibram, 20I4).

Hay que destacar de la PNM el énfasis en la dimensión educativa, relacionado directamente a tres de los siete ejes programáticos de esa política, comprometidos con la formación y capacitación de profesionales de museos, con el incentivo a la creación de cursos de grado y de posgrado en Museología y con el incentivo a la producción de investigaciones y de nuevas tecnologías en conservación, documentación y comunicación (Iphan, 2003).

La función social de los museos también era un aspecto prioritario de la PNM. Desde ella se desarrollaron distintas acciones, como convocatorias para el incentivo a la creación de museos en ciudades donde esos no existían (Covocatoria Más Museos) y el Programa Puntos de Memoria, que apoyaba la creación de museos comunitarios desde la lógica de la Museología Social, transformándose en importante herramienta para alcanzar los derechos de memorias y de patrimonios.

Calabre (2007) subraya que, por primera vez, se podían notar avances concretos para que la cultura fuese tema de la agenda política de gobierno. No obstante, para que las políticas fuesen de echo consolidadas quedaba mucho por hacer. La autora señala que era necesario garantizar los presupuestos precisos para el funcionamiento adecuado de las entidades y el desarrollo y mantenimiento de los distintos programas y proyectos propuestos, implantar de hecho el PNC, reglamentar las competencias de los gobiernos federal, estaduales y municipales respecto a la agenda de la cultura, o sea, normatizar el SNC, e 
implantar estrategias para garantizar la inclusión digital y mejorar la gestión de la información sobre el sector.

De hecho, aunque aumentaron los presupuestos para el área, no han sido suficientes para consolidar, en la década de 20ı, las políticas públicas y las entidades de cultura. En el sector museal, faltó reforzar los instrumentos institucionales, de democratización y financiación que componen el modelo de la PNM. De hecho, el IBRAM, en sus II años de existencia, jamás ha alcanzado los recursos financieros y humanos precisos para poner en marcha las políticas. A pesar de todo, se concretaron importantes acciones, como la regularización de los museos (Decreto no 8.I24/I3), la creación la Política de Educación Museal/ PNM (gracias al activismo y colaboración de las/los agentes no estatales) y del Programa Saber Museo que, desde una plataforma virtual, ofrece materiales y talleres de capacitación.

La conyuntura política y económica del país, sumada a las dificultades de sector cultural, derivadas de la incapacidad de resolver problemas presupuestarios, estructurales y operacionales que afectaron al funcionamento de las entidades y la consolidación de las políticas propuestas en la decada anterior, ha debilitado y puesto en riesgo todo el sector. El hito trágico y traumático de esa conyuntura es el incendio del Museo Nacional, en 2018.

La debilitación del área, su desinstitucionalización, con el agravamiento de las deficiencias presupuestarias, estructurales y operacionales ha empeorado desde la disminuición del diálogo con el gobierno federal. En 2019 se extinguió el Ministerio de Cultura una vez más ${ }^{\text {II }}$. Su estructura ha sido transformada en Secretaría, actualmente vinculada al Ministerio de Turismo, así como los organismos que estaban asociados a este, tal como el IPHAN y el IBRAM. El escenario actual va marcado por la interrupción de programas y proyectos, la desarticulación del SBM, del SNC y de otros grupos que componen el sector cultural. Luego no existió la sinergia necesaria para la revisión del PNC y planes sectoriales adjuntos, tampoco la proposición de nuevas estrategias para el período 2020-2030, desde la representatividad y las metodologías participativas utilizadas en la primera década del siglo XXI.

Pero este contexto deriva también de los ataques a las entidades por parte del Estado y, principalmente, las arremetidas, por parte del mismo poder, contra los valores, las directrices y los ejes que fundamentan las políticas públicas planteadas al inicio del siglo XXI. Concretamente, el estado del arte del sector cultural es un hito excepcional en la trayectoria del ramo. Las presiones exógenas, procedentes de las directivas del gobierno, ponen en riesgo la afinidad que las políticas públicas de Brasil han tenido con los valores y las directrices de las convenciones de las organizaciones internacionales (hasta con la Declaración Universal de los Derechos Humanos) incluso durante los períodos dictatoriales.

II. El Ministerio se extinguió en I990 (recreado en 1994), 2016 (recreado el mismo año) y 2019, cuando ha sido transformado en Secretaría Especial de Cultura. 
El museólogo Saulo Moreno (2020) dice que el país necesita de políticas de memoria y de patrimonio. Sin embargo, esas aún existen. No se consolidaron como políticas de Estado, pero siguen en los discursos y las prácticas de las/ los agentes, estatales o no. Hoy, las entidades y las/los trabajadoras/es de la cultura y del patrimonio se encuentran en situación de gran vulnerabilidad, degenerada desde la pandemia del COVID-rg. Quedó por hacer la articulación entre ellas/ellos para replantear el PNC, que significa tener más condiciones de aumentar los presupuestos y luchar por una arquitectura jurídica-institucional efectiva. También existe el riesgo de sustitución de los valores y los principios que fundamentan las políticas y las prácticas por otras nociones que no coinciden con los derechos de memoria, de patrimonio y de cultura.

De hecho, se puede decir que el actual es un momento insólito y de ruptura con los valores y las decisiones institucionales fundadoras del sector cultural, en especial, del patrimonio y de los museos. Desde el institucionalismo histórico, se observa en las políticas públicas del país la tendencia de coincidir con las directrices internacionales para el ramo y también la conformación de un corpus institucional dirigido por expertos en los temas. Ahora, es todo lo contrario, pues están en riesgo los derechos culturales y de memoria de los distintos segmentos sociales (como los pueblos originarios y los afrodescendientes) y se juramentaron agentes ineptos y no cualificados para asumir los respectivos roles.

\section{La definición-misión de Museo en el Brasil pos pandémico}

La pandemia del COVID-I9 atraviesa el proceso de reflexión y disputa de narraciones sobre el museo en el siglo XXI. Hay que considerar y hablar de qué museo queremos, justo en un momento de grandes cambios. Es decir, la pregunta “ ¿Cualés son las principales funciones y características del museo en el siglo XXI?" hay que contestarla teniendo en cuenta tanto los retos impuestos por virus que nos impone otras formas de ser y de estar en el mundo así como los efectos de la crisis económica y social provocada por la pandemia.

En Brasil, nos toca enfrentar el reto de seguir con las ilusiones y propuestas condensadas en la definición planteada por el ICOM en una conyuntura distópica, donde la peste "expone la necropolítica en curso, que predice que las vidas pueden descartarse siguiendo la lógica del sacrificio neoliberal (Mbembe \& Meintejes, 2003; Mbembe, 2020)" (Saladino \& Muniz, 2020, p.I) y que suele se fortalecida por la biopolítica, que impone nuevos límites de nuestros cuerpos (mascarillas, guantes etc) y sobre ellos (distancia social).

Es decir, hay que reflexionar sobre las posibilidades reales de concretar y desarrollar estrategias para lograr los ejes de los museos del siglo XXI, que van más allá de las buenas prácticas desde la ejecución de las funciones básicas de esas entidades y que pretenden consolidar el rol de los museos para la transformación de la sociedad, como propone la definición presentada por el ICOM en 20I9: 
"Los museos son espacios democratizadores, inclusivos y polifónicos para el diálogo crítico sobre los pasados y los futuros. Reconociendo y abordando los conflictos y desafíos del presente, custodian artefactos y especímenes para la sociedad, salvaguardan memorias diversas para las generaciones futuras, $y$ garantizan la igualdad de derechos $y$ la igualdad de acceso al patrimonio para todos los pueblos.

Los museos no tienen ánimo de lucro. Son participativos y transparentes, $y$ trabajan en colaboración activa con y para diversas comunidades a fin de coleccionar, preservar, investigar, interpretar exponer y ampliar las comprensiones del mundo, con el propósito de contribuir a la dignidad humana y a la justicia social, a la igualdad mundial y al bienestar planetario." (ICOM, 2019)

\section{9}

Está claro que la crisis política y económica obliga al sector cultural, y luego a los museos, retos dificilísimos de confrontar. Sin embargo, desde el Institucionalismo Histórico, se observan de la trayectoria del área de los museos, de los valores que fundamentan las políticas y las decisiones institucionales, algunos aspectos afines con la definición de museo propuesta el 20r9, que subraya el carácter político y la función social de esa entidad.

Teniendo en cuenta la "dependencia de la trayectoria", es decir, la tendencia de mantener, a lo largo del tiempo, los valores correspondientes a las primeiras opciones institucionales, conservados en las prácticas rutinizadas, se puede observar que las elecciones del sector de museos en Brasil destacan la función social de los museos, con énfasis en su competencia educativa. El área museológica del país ha sido escenario de importantes hitos para el tema, como el Seminario Regional de UNESCO para la función educativa de los museos (1958) y el I Encuentro Internacional de Ecomuseos (I992). También ha actuado como laboratorio para interesantes experimentos en educación patrimonial y museal (destaca la creación de la PNEM y las articulaciones para el reconocimiento y la profesionalización de los educadores de museos) y figurado en la Museología Social, cuyos ejes se incorporaron en la PNM y cuyos valores siguen orientando las/los agentes institucionales, estatales o no. En síntesis, las opciones institucionales del sector de museos en Brasil marcan la dimensión educativa del museo, confirmadas en las políticas del sector y respectivos instrumentos y también por las recientes articulaciones de CECA/ ICOM/Brasil y de la REM para que la palabra "educación" fuese incorporada en la propuesta de definición recién presentada por el ICOM.

También es importante marcar las decisionese institucionales del área de los museos en el país por coincidir con las directrices y recomendaciones del ICOM, que se puede verificar en la influencia de la definición de museos del 
ICOM (de 1974, que pasó por algunas alteraciones en 2007) en la definición presente en el artículo i e la Ley n. Ir.904/o9:

"Para los efectos de esta Ley, se considera que los museos son instituciones sin fines de lucro que conservan, investigan, comunican, interpretan y exhiben, con fines de conservación, estudio, investigación, educación, contemplación, y turismo, colecciones de valor histórico, artístico, científico, técnico o de cualquiera otra índole cultural, abierta al público, al servicio de la sociedad y de su desarrollo.

Párrafo único: Esta Ley insertará las instituciones y los procesos museológicos orientados a trabajar el patrimonio cultural y el territorio con miras al desarrollo cultural, socioeconómico y la participación comunitaria." (Art. $1^{\circ}$ de la Ley $\left.n^{\underline{0}} 11.904 / 09\right)$.

Por eso, y desde una mirada más positiva, este puede ser un nomento oportuno para revisar la nueva definición propuesta por el ICOM. Porque, en el Brasil pandémico y pos pandémico, aún es más importante tener museos que asumen su dimensión política y educativa, actuando como espacios donde los discursos de las memorias y de los derechos humanos (con énfasis en los culturales) "alimenten una dimensión universalizante que reconozca la particularidad pero sin objetificarla" (Huyssen, 20I4, p. 210) ${ }^{12}$. Es decir, que los museos se responsabilicen por el proceso político de selección de memorias, que es la gestión del patrimonio cultural, y refuercen y multipliquen las experiencias de descolonización de sus discursos y prácticas, concentrándose más en los procesos que en las cosas.

Luego, las implicaciones en el uso de la definición de museo propuesta por el ICOM en 2019 en el escenario actual del país conllevan a la resistencia y a la resiliencia, por parte de todas/os agentes (estatales o no) para el mantenimiento de la PNM, que pasa por un proceso de debilitación. Consideramos que la nueva definición de museo, especialmente los puntos relacionados a los valores (la dignidad humana, la justicia social, la igualdad mundial y el bienestar global) está en gran consonancia con los principios, las directrices y los ejes estratégicos de la PNM. Luego, puede ser una forma de soportar las presiones exógenas desde el sector político, puesto que la política del sector de museos no ha sido completamente destruída ni abandonada, sigue en el discurso oficial del IBRAM y en las prácticas e ilusiones de las/los agentes del área.

Concretamente, a nivel legal y administrativo consiste en mantener las leyes y reglamientos del sector, puesto que están fundamentados en los principios del

I2. Sobre el tema de los límites y retos de la relación entre derechos humanos y políticas de la memoria, véase la obra del filólogo, Andreas Huyssen (2014). 
derecho a las memorias y a los patrimonios, de los museos como herramientas de cambio y justicia social, de valorización de la dignidad humana, de promoción de la ciudadanía, de incentivo a la participación comunitaria en los procesos museológicos y de desarrollo cultural y socioeconómico ${ }^{\text {I3 }}$. Luego, puede ser esta una estrategia para sostener algunas acciones de incentivo a los museos, especialmente los museos comunitarios y processos museológicos, que están considerados por la PNM, pero necesitan mayor apoyo financeiro.

A nivel práctico, se trata de intentar fortalecer las articulaciones de las entidades y las/los agentes no estatales para reivindicar que se mantengan los ejes de la $\mathrm{PNM}^{14}$, luchando por garantizar la conservación de la función educativa, la promoción de la inclusión digital (puesto que por un largo tiempo los museos estarán restringidos a desarrollar actividades on line) y el desarrollo de actividades de empoderamiento social, desde metodologías participativas que impulsen las relaciones entre museos, comunidades, patrimonios y ambiente (ciudades y medio rural).

En los tiempos pos pandémicos, toca que los museos se involucren más en el bienestar de las personas y la promoción de la calidad de vida. Entonces es importante que actúen desde las propuestas transnacionales, como la Convención sobre la protección y la promoción de la diversidad de las expresiones culturales (UNESCO) y la Agenda $2030(\mathrm{ONU})^{15}$. Estas proposiciones coinciden con y son motivadas por la definición propuesta por el ICOM, pues se tratan de estrategias de acercamiento de los museos a las comunidades en un nivel integral y de fortalecimiento de la ciudadanía.

Esta mirada termina por evocar las palabras de la museóloga Waldisa Russio que inauguran este texto por señalar la importancia de los museos en este mundo en transición. Ahora que nos toca a todos revisar estructuras, normas, patrones y límites (espaciales y corporales), los museos, como entidades y procesos de musealización de cosas e ideas que constituyen nuestros mundos y humanidades son herramientas clave para planear una nueva utopía, marcando su posición política sobre su función social.

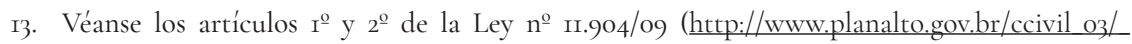
Ato2007-2010/2009/Lei/Lirgo4.htm).

I4. Esta propuesta surgió en los debates sobre las políticas de museos provocados durante el directo del cientista sociólogo Átila Tolentino, promocionada por el Museo de Arte de la Universidad Federal de Ceará, en 28 de mayo de 2020 .

I5. Las políticas públicas para museos en Brasil buscan seguir los documentos y programas internacionales, como la Agenda 2I. La respuesta para ello fue la creación del Programa Socioambiental, parte de la estructura del Plan Museológico de los museos brasileños (Saladino, 20r4; Ibram, 20r6). 


\section{Referencias}

Bruno, M. C. O. (Ed.). (20roa). Waldisa Rússio Camargo Guarnieri: textos e contextos de uma trajetória profissional (Vol. I, pp.45-56). São Paulo, Brasil: Pinacoteca do Estado; Secretaria de Estado de Cultura; Comitê Brasileiro do Conselho Internacional de Museus.

Bruno, M. C. O. (Ed.). (2orob). Waldisa Rússio Camargo Guarnieri: textos e contextos de uma trajetória profissional (Vol. I, pp.I23-I26). São Paulo, Brasil: Pinacoteca do Estado; Secretaria de Estado de Cultura; Comitê Brasileiro do Conselho Internacional de Museus.

Calabre, L. (2007). Políticas de Cultura no Brasil: balanço e perspectivas. En Rubim, A. A. C. (Ed.). Políticas culturais no Brasil. Salvador, Brasil: EDUFBA.

Calabre, L. (2013). Participação social na construção de Plano Setoriais de Políticas Públicas: um estudo do Plano Nacional de Cultura. VI Congresso CONSAD de Gestão Pública. Brasilia. Recuperado el 20 de abril de 2020 de http://consad.org.br/wp-content/uploads/2013/05/o66-PARTICI$\mathrm{PA} \% \mathrm{C}_{3} \% 87 \% \mathrm{C}_{3} \% 83 \mathrm{O}-\mathrm{SOCIAL}-\mathrm{NA}-\mathrm{CONSTRU} \% \mathrm{C}_{3} \% 87 \% \mathrm{C}_{3} \% 83 \mathrm{O}-$ DE-PLANOS-SETORIAIS-DE-POL\%C3\%8DTICAS-P\%C3\%9ABLICAS-UM-ESTUDO-DO-PLANO-NACIONAL-DE-CULTURA.pdf

Calabre, L. (20r4). Política Cultural em tempos de democracia: a Era Lula. Ver. Inst. Estudos Brasileiros, São Paulo, 58, 37-I56. https://www.scielo.br/ scielo.php?script=sci_arttext\&pid=SoO20-38742014000100008

Definición de Museo. (2019). ICOM. Consejo Internacional de Museos. Recuperado el 3I de agosto de 2020 de https://icom.museum/es/recursos/normas-y-directrices/definicion-del-museo/

Estatuto de Museus - Lei 11.904/o9 / Lei noํ⒒904, de 14 de janeiro de 2009. (2009). JusBrasil. Recuperado el 3I de agosto de 2020 de https://presrepublica. jusbrasil.com.br/legislacao/92498/estatuto-de-museus-lei-II904-09

Fonseca, C. L. (2005). O patrimônio em processo: trajetória da política federal de preservação no Brasil. Río de Janeiro: Editora UFRJ/MinC-IPHAN.

García Canclini, N. (2005). Definiciones en transición. En Mato, D. (Ed.). Cultura, política y sociedad Perspectivas latinoamericanas. Buenos Aires: Argentina. CLACSO, Consejo Latinoamericano de Ciencias Sociales, $57-67$.

Hall, P. A., \& Taylor, R. C. R. (2003). As três versões do Neoinstitucionalismo. Lua Nova, 58, 193-223. Recuperado de https://www.scielo.br/pdf/ln/n58/ aion58.pdf 
História da Museologia (2017). [Entrada de blog]. Recuperado el I de septiembre de 2020 de https://historiadamuseologia.blog/terminologia/ museal-x-museologico/.

Huyssen, A. (20I4). Culturas do passado-presente: modernismos, artes visuais, políticas da memória. Río de Janeiro: Contraponto/MAR.

IBRAM. (20I4). Museus e a dimensão econômica: da cadeia produtiva à gestão sustentável. Brasilia, Brasil: Instituto Brasileiro de Museus.

IBRAM. (20ı6). Subsídios para elaboração de Planos Museológicos. Brasilia, Brasil: Instituto Brasileiro de Museus. Recuperado de https://www.museus. gov.br/wp-content/uploads/20I7/o6/Subs\%C3\%ADdios-para-a-elabora\% $3 \% \mathrm{~A}_{7} \% \mathrm{C}_{3} \% \mathrm{~A}_{30}$-de-planos-museol\%C3\%B3gicos.pdf

Íntegra do discurso de posse do Ministro da Cultura, Gilberto Gil. (2003). Carta Maior. Recuperdo el 25 de abril de 2020 de https:// www.cartamaior.com.br/?\%2FEditoria\%2FMidia-e-Redes-Sociais\%2Fintegra-do-discurso-de-posse-do-ministro-da-cultura-Gilberto-Gil\%2 $\mathrm{F}_{12} \%_{2} \mathrm{~F}_{5} 623$ \&fbclid=IwAR 8 Uredmdonvms6rhHMvMbXoCNBx_hmjLxCraDp4wovlInuP8WKvJlMl8A

IPHAN (2003). Política Nacional de Museus. Memória e Cidadania. Brasilia: IPHAN. Recuperado de https://www.museus.gov.br/wp-content/ uploads/20Io/o2/politica_nacional_museus_2.pdf

Moreno, S. (2020, Abril 24). Precisamos de uma política de memória e de patrimônio, defende o museólogo Saulo Moreno. [Fábio Sena, do micro ao macro.] Recuperado el 5 de mayo de 2020 de https://blogdofabiosena. com.br/v3/precisamos-de-uma-politica-de-memoria-e-patrimonio-defende-o-museologo-saulo-moreno/

Nogueira, A. G. R. (2005). Por um inventário dos sentidos: Mário de Andrade e a concepção de patrimônio e inventário. São Paulo, Brasil: HUCITEC/FAPESP.

Nora, P. (1993). Entre memória e história: a problemática dos lugares. Profissão História, Io, 7-28. Recuperado de https://revistas.pucsp.br/index.php/ revph/article/viewFile/I2тог/8763

Nunes, G. (2019). Os Sistemas de Museus - construção de uma política para o setor museológico no Brasil, em Minas Gerais e em Ouro Preto, experiências e modelos de gestão nas três esferas de governo. IV SEBRAMUS, Brasilia, DF, p.206-2017. Recuperado de http://sebramusrepositorio.unb. br/index.php/Isebramus/ISebramus/paper/view/449/2I

Rangel, M., \& Nascimento Júnior, J. (2015). A trajetória da Política Nacional de Museus: impactos sobre o setor museológico. En Granato, M. (Ed.). Museologia e Patrimônio. (pp.297-315). Río de Janeiro, Brasil: MAST. Recuperado de http://site.mast.br/hotsite_mast_3o_anos/pdf/volume_or.pdf 
Rubim, A. A. C. (2006). Políticas culturais entre o possível e o impossível. II Encontro de Estudos Multidisciplinares em Cultura. Salvador (p.I-I7). Recuperado el 27 de abril de 2020 de https://politicasculturais.files.wordpress. com/200g/o3/politicas-culturais-entre-o-possivel-e-o-impossivel.pdf

Rubim, A. A. C. (2007). Políticas culturais no Brasil: tristes tradições, enormes desafios. Rubim, A. A. C. (Ed.). Políticas culturais no Brasil (p.II-36). Salvador, Brasil: EDUFBA,

Saladino, A. (2014). The Republic Museum's Social Environmental Programme: proposal and actions for social change. Museum International, ICOM. Recuperado de https://onlinelibrary.wiley.com/doi/abs/ıo.IIII/ muse.I2O2I

Saladino, A., \& Muniz, T. (2020). No meio do caminho tinha um vírus: reflexões sobre os impactos do COVID-I9 sobre o patrimônio cultural. Revista Museu, r. Recuperado de http://revistamuseu.com.br/site/br/artigos/I8de-maio/I8-maio-2020/8510-no-meio-do-caminho-tinha-um-virus-reflexoes-sobre-os-impactos-do-covid-Ig-sobre-o-patrimonio-cultural.html

Simis, A. (2007). A política cultural como política pública. En A. A. C. Rubim (Ed.). Políticas culturais no Brasil. (pp.I33-155). Salvador, Brasil: EDUFBA. 